\title{
The Eradication of the Immunodeficiency Virus Human (HIV/AIDS) Transmission from Mother-to-Child (ETMC) in the Maternity Ward at the Ratoma Medical Centre, Conakry, Guinea
}

\author{
Boubacar Siddi Diallo1*, Mamadou Samba Keita', Ibrahima Sory Balde², Mamadou Hady Diallo', \\ Ibrahima Conte ${ }^{2}$, Ousmane Balde', Ibrahima Sylla², Oumou Hawa Bah', Moussa Kante1, \\ Telly Sy², Yolande Hyjazi¹, Namory Keita ${ }^{1}$
}

\begin{abstract}
${ }^{1}$ University Department of Gynecology-Obstetrics, Donka National Hospital, Conakry, Guinea
${ }^{2}$ University Department of Gynecology-Obstetrics, Ignace Deen National Hospital, Conakry, Guinea

Email: `tounty1@yahoo.fr, keitamamadousamba@yahoo.fr, baldeisory@yahoo.fr, hadydiallo@yahoo.fr, conteib1976@gmail.com, baldeousmane04@gmail.com,dribra62@yahoo.fr, camarahawa2002@gmail.com, kantemoussa642@gmail.com, sytelly@yahoo.fr, namoryk2010@yahoo.fr
\end{abstract}

\begin{abstract}
How to cite this paper: Diallo, B.S., Keita, M.S., Balde, I.S., Diallo, M.H., Conte, I., Balde, O., Sylla, I., Bah, O.H., Kante, M., Sy, T., Hyjazi, Y. and Keita, N. (2019) The Eradication of the Immunodeficiency Virus Human (HIV/AIDS) Transmission from Mother-to-Child (ETMC) in the Maternity Ward at the Ratoma Medical Centre, Conakry, Guinea. Open Journal of Obstetrics and Gynecology, 9, 715-721.

https://doi.org/10.4236/ojog.2019.95071
\end{abstract}

Received: March 21, 2019

Accepted: May 24, 2019

Published: May 27, 2019

Copyright $\odot 2019$ by author(s) and Scientific Research Publishing Inc. This work is licensed under the Creative Commons Attribution International License (CC BY 4.0).

http://creativecommons.org/licenses/by/4.0/

cC) (7) Open Access

\begin{abstract}
Objectives: The objectives of this article are to: 1) Determine the prevalence of parturient that escapes from the ETME, 2) Determine the rate of acceptability or non-acceptability of the HIV tests, 3) Describe the epidemiological profile and 4) Describe the factors explaining the lack of screening during pregnancy. Methodology: This report is based on an eventual descriptive study carried out in the Maternity Ward at the Ratoma Medical Centre for the past six months. The study took place over six (6) months from June 15 to December 15, 2016. The data were collected by individual interviews using a data collection sheet and prenatal consultation booklet that were administered to parturients in their language of comprehension. Each unscreened parturient received in the delivery room or in immediate postpartum received pre- and post-test HIV/AIDS counseling with immediate announcement of the outcome for all those who accepted the principle. For parturients who were in the active phase of work, counseling/testing was done in the immediate postpartum period. The data were manually collected from the pre-established fact sheets, captured using the Word, Excel and PowerPoint software packages of the 2007 Office and analyzed by the Epi-Info software (version 3.5.4). The limitations of the study were the lack of adequate room for the HIV testing council, the refusal of HIV testing by some parturients and the lack of achievement of CD4 levels in the hospital laboratory. Outcomes: The survey indicated that out of the $41.80 \%$ (177/423) of pregnant
\end{abstract}


women that have recently given birth, ignore their HIV status. About 36.90\% $(66 / 177)$ rejected the screening and the $6.4 \%(7 / 111)$ that accepted were HIV/AIDS positive. The epidemiological study revolved around the following categories of women aged between 24 and 33 (42.85\%), 1) Married (100\%), 2) Housewives (57.14\%), 3) Out-of-school (57.14), 4) Lack prenatal follow-up (42.85\%), 5) Ignorance of the existence of HIV (71.42\%). Reason Invoked for the Unawareness: No screening was proposed for prenatal follow-up (90.40\%). Conclusion: The HIV testing approach in the work room could serve as a catch-up strategy to reduce vertical transmission and thus increase the operational coverage of the PMTCT service. The upgrading providers of basic facilities would be necessary in order to offer the HIV screening in refocused prenatal consultations, which could reduce the catch-up/contamination in the work room.

\section{Keywords}

Catch-Up, HIV, Work Room

\section{Introduction}

The eradication of the human immunodeficiency virus (HIV/AIDS) Transmission from Mother-to-Child (ETMC), in its comprehensive approach is an intervention package in view of preventing or reducing the transmission of the HIV/AIDS from the mother to the child [1]. The catch-up of the ETMC is a measure consisting the rapid screening counselling of the HIV in the workroom for women who are unaware of their seropositive status and to put the seropositive ones and their newly born babies under intensive care anti-retrovirus RVs [2]. These prophylactic practices have considerably reduced the vertical transmission of HIV/AIDS in developed countries especially in France and in the United States at least to $2 \%$ [3].

In Africa, the HIV screening services have been introduced at the prenatal consultations level (ANC). However, the coverage of these services remains insufficient. As a result, many women still give birth without knowing their HIV status and cannot benefit from adequate prevention measures in this context [4].

The survey which was carried out in 56 ETMC sites in Benin in 2008, shows that the HIV prevalence among pregnant women has attained 3.9\% [5]. They were all under antiretroviral treatment.

The sero-survey sentinel report in Ivory Coast in 2008 indicated that HIV seroprevalence has attained $4.5 \%$ among pregnant women aged 15 - 49. Almost all of these women have received antiretroviral treatment [6].

The first investigation in Guinea had given prevalence median rates of $2.8 \%$ and $2.5 \%$ among pregnant women in 18 health centres in 2004 and 2008 [7].

Thus, we carried out this study with the following objectives: to determine the prevalence of parturient who escapes ETME, determine the rate of acceptability or reaction to HIV tests, describe the epidemiological profile and describe the 
factors explaining the lack of screening during pregnancy.

\section{Methodology}

It was a descriptive prospective study of a duration of 06 months conducted at the maternity ward of the Ratoma CMC which is a 2nd level structure in Guinea.

The study focused on a continuous series of 423 parturient received in the working room. Included in the study were all women who had come to give birth despite age, residence, who did not know their HIV status and had accepted the screening. Any parturient who refused to do part of the study was not included in the study. We conducted a comprehensive recruitment of cases according to defined criteria as mentioned above.

The study took place over six (6) months from June 15 to December 15, 2016.

The data were collected by individual interviews using a data collection sheet and prenatal consultation booklet that were administered to parturients in their language of comprehension. Each unscreened parturient received in the delivery room or in immediate postpartum received pre and post-test HIV/AIDS counseling with immediate announcement of the outcome for all those who accepted the principle.

For parturients who were in the active phase of work, counseling/testing was done in the immediate postpartum period.

The data were manually collected from the pre-established fact sheets, captured using the Word, Excel and power point software packages of the 2007 Office and analyzed by the Epi-Info software (version 3.5.4).

The limitations of the study were the lack of adequate room for the HIV testing council, the refusal of HIV testing by some parturients and the lack of achievement of CD4 levels in the hospital laboratory.

\section{The variables studied were:}

- Prevalence, acceptability or repressive to the screening test, result of the test of screening

- Epidemiological: maternal age, marital status, level of education, occupation

- Clinical: prenatal follow-up, level of awareness about HIV, HIV status, reasons for unawareness of HIV status, test proposal, test result.

\section{Results}

In our study, 423 patients participated in the study of which 177 were unaware of their HIV status (41.8\%) and 246 were aware of their HIV status. Among the 177 who did not know their status; 66 refused the test (37\%) and 111 accepted the test (63\%). Among those who accepted the test; 104 were negative (93.6\%) and 07 were positive (6.4\%).

\subsection{Prevalence}

The survey indicated that out of the $41.80 \%$ (177/423) women who have recently given birth, ignored their HIV status. 


\subsection{Acceptability or Non-Testing Rate}

The survey indicated that out of the $41.80 \%$ (177/423) women who have recently given birth, ignored their HIV status and $36.90 \%$ (66/177) were repressive to the test.

\subsection{Result of the Testing Test}

The survey indicated that $6.4 \%$ (7/111) among the parturient who have accepted the screening test were HIV/AIDS positive.

\subsection{The Epidemiological Profile}

1) Age: The most concerned amongst age groups are from 24 to 33 with an average age of (42.85\%) 24.75 years and 14 and 40 years beyond.

2) Profession: $57.14 \%$ of the most concerned were Housewives.

3) Level of education: $57.5 \%$ of the majority of our patients were illiterate

4) Matrimonial status: $100 \%$ of the patients represented were Brides.

\subsection{Clinic}

- The PRENATAL SURVEY specified that $42.85 \%$ of the Patients accounted for were without prenatal care.

- HIV/AIDS AWARENESS LEVEL: $71.42 \%$ of the Women in the roomhad a low level of awareness about HIV.

- STATUS OF UNAWARENESS: The main reason invoked is the non-screening proposal for prenatal follow-up which raised up to $90.40 \%$.

\section{Discussion of the Results}

In our study, 423 patients participated in the study of which 177 were unaware of their HIV status (41.8\%) and 246 were aware of their HIV status. Among the 177 who did not know their status; 66 refused the test (37\%) and 111 accepted the test (63\%). Among those who accepted the test; 104 were negative (93.6\%) and 07 were positive $(6.4 \%)$.

\subsection{Prevalence}

Observation had it that about $41.80 \%(177 / 423)$ of women that have recently given birth, ignored their HIV status. Our findings revolve between DEMBELE B. [8] and RAKOTONIRINA EJ et al's [9] in their respective surveys with 4.34\% and $72 \%$.

The non-completion of prenatal care, the repudiation of some women to be diagnosed and the absence and/or insufficiency of screening tests could justify these results.

\subsection{Acceptability or Repressive to the Screening Test}

The survey indicated that about $41.80 \%(177 / 423)$ of women that have recently given birth, ignored their HIV status. $36.90 \%$ (66/177) were repressive to the 
screening test and among those diagnosed 6.4\% (7/111) were HIV/AIDS positive. This result is similar to that found by LAMAH L. [10] who claimed about $35.3 \%$ and above of what was reported by DEMBELEB. with 3\%. The notion of fatality associated with HIV/AIDS, the desire to have a positive result and the fear of being rejected or dismissed by the spouse as well as the fear of discrimination towards the community could explain this repudiation.

\subsection{Result of the Screening Test}

Among the parturient who have accepted the screening test, 6.4\% (7/111) were HIV/AIDS positive. This result is in accordance DEMBELE B's [8] and Mwembo Tambwe A.N.K. et al.'s findings [11] in their respective surveys with $10 \%$ and $4 \%, 8 \%$. At National level, this result is far superior to that of Guinea's DHS III, which reports a prevalence of $2 \%, 8 \%$ among women.

\subsection{He Epidemiological Profile}

1) Age: The most concerned amongst age groups are from 24 to 33 with an average age of (42.85\%) 24.75 years and 14 and 40 years beyond. This result is in accordance with DEMBELE B's [8] and Mbang D.D [12] et al.'s findings [11] in their respective surveys with $51.4 \%$ and $33.8 \%$. This high proportion of HIV/AIDS among young women could be explained not only by the fact that they are highly involved in promiscuous sexual behaviour and have no notion of preventive methods, but also their early involvement in marriage with sexually active men, which exposes them to a major risk of contamination.

2) Profession: the most concerned were Housewives with an average of $57.14 \%$. This result is similar to DEMBELE B. findings [8] 54.1\%.

The consequence could be explained by not only the low level of education of these women, the lack of means, and the influence of the society but also the partner's refusal to use the condom during sexual intercourse.

3) Level of education: $57.5 \%$ of the majority of our patients were illiterate. This result is lower than that found by Mwembo-Tambwe A.N.K et al. [11] in Lubumbashi $92.6 \%$. This result reflects the realities socio-cultural activities in Africa and particularly in Guinea where the rate of enrolment of girls is only $41 \%$ according to EDSG III [13].

4) Matrimonial status: Brides represented $100 \%$ of the patients.

This result is similar to those reported by LAMAH L. [10] and Mwembo-Tambwe A.N.K et al. [11] with $70.65 \%$ and $91.1 \%$ respectively. ESSIDAGUI/2001 [14] found a similar result 92\%. This could be explained by the fact that in our communities it is frowned upon that a single woman conceives on the one hand and on the other hand, the use of means of protection (condom) is almost non-existent even in polygamous homes

\subsection{Clinic}

PRENATAL SURVEY: Patients without prenatal care accounted for $42.85 \%$. 
Reasons that prevented HIV testing include: non-provider testing during prenatal follow-up, lack of information, and lack of interest in the test. These patterns are similar to those advanced by Moth et al. [15] Kalichman et al. [16] and Muchedji and $\mathrm{Al}$ [17] in their respective studies.

- THE HIV/AIDS AWARENESS LEVEL: Women in the workroom had a low level of knowledge about HIV (71.42\%). Similar results were obtained by Perez et al. [18]. The lack of information on the need for NPCs and the lack of training of health providers on the refocused NPC would contribute to this result. This shows, on the one hand, the need for an awareness of the population centered on the ETME and, on the other hand, a service organization that can increase its geographical, socio-cultural and financial accessibility.

REASON INVOKED FOR THE UNAWARENESS OF STATUS: The main reason given is the non-screening proposal (90.40\%) for prenatal follow-up. Recent studies have shown a correlation between HIV testing in pregnant women and the strategy used. Programs that wait until the demand comes from the pregnant woman have low prevalence of screening compared to those who routinely offer the test to all pregnant women with routine ANC [18]. However, the proposal should be made in such a way as to allow the pregnant woman to freely accept this test. In the same vein, a poor quality service may lead pregnant women to abandon prenatal consultations after the results of screening [16].

\section{Conclusion}

The HIV testing approach in the work room could serve as a catch-up strategy to reduce vertical transmission and thus increase the operational coverage of the PMTCT service. Upgrading providers of basic facilities would be necessary to provide HIV testing in refocused prenatal consultations, which could reduce catch-up in the work room.

\section{Conflicts of Interest}

The authors declare no conflicts of interest regarding the publication of this paper.

\section{References}

[1] National Council of Fight against AIDS (2009) Standards and Procedures for the Prevention of Mother-to-Child Transmission (PMTCT) of HIV. Guinea, 6-16.

[2] Ministry of Public Health in Guinea (2005) Reference Manual for Health Providers. PNMSR 2005/CPN Refocused/Reference Manual, 9.

[3] Becquet, R. and Lorey, V. (2007) Challenges in Preventing Mother-to-Child Transmission of HIV in Africa. Medical Care, 3-4.

[4] Mwembo-Tambwe, A., et al. (2012) Childbirth with Unknown HIV Status in Lubumbashi, DR Congo: Proportion and Determinants. Pan African Medical Journal, 1.

[5] Cairn Info (2008) Prevention of Mother-to-Child Transmission of HIV: A State of 
Play at the Benign. Public Health, 6.

[6] National AIDS Council (2014) Follow-Up of the AIDS Policy Statement June 2011. UNAIDS Cote d'Ivoire. National Report 2014, 10-13.

[7] National AIDS Committee (2008) National Sentinel Surveillance Survey of HIV and Syphilis. ENNS. Guinée 2008-2004. 8-9.

[8] Dembélé, B. (2010) HIV Screening in the Delivery Room at the Maternity Hospital of the Reference Health Center of Commune V of Bamako District. Medical Thesis, Bamako 2010, 23-30.

[9] Coll, R.E. (2011) The Challenge of Preventing Mother-to-Child Transmission of HIV in Madagascar. Medicine of Black Africa, 8-9.

[10] Lamah, L. (2013) Determining the Refusal of HIV Testing among Pregnant Women in the Gynecology and Obstetrics Department of Donka National Hospital. Medicine Thesis, UGANC/FMPOS 2013, 23-30.

[11] Mwembo Tambwe, A.N.K., et al. (2013) HIV Testing in the Working Room in Lumumbashi, Democratic Republic of Congo. A Catch-Up Strategy in the Context of Prevention of Mother-to-Child Transmission. Journal of Epidemiology and Public Health Reviews, 61, 21-27. http://www.sciencedirect.com

[12] Mbang Dono, D. (2012) Current State of Prevention of Mother-to-Child Transmission of HIV/AIDS in Conakry. Thesis of Medicine, UGANC/FMPOS2011. No. 248, 8-12.

[13] National Statistical Office, ORC Macro (2006) Demographic and Health Survey in GUINEA (EDSGIII-2005), No. 24.

[14] PNPCSP Guinea. (2002) National HIV/AIDS Seroprevalence Survey in Guinea (ESSIDAGUI/2001). Final Report.

[15] Moth, I.A., Ayayo, A.B.C.O. and Kaseje, D. (2005) Assessment of Utilization of PMTCT Services at Nyanza Provincial Hospital, Kenya. SAHARA-J: Journal of Social Aspects of HIVI AIDS, 2, 224-250.

https://doi.org/10.1080/17290376.2005.9724847

[16] Barrigye, H., Levin, J., Mather, D., Tindiwegi, G., Atuhumuza, E., Nakibinge, S. and Grosskurth, H. (2010) Operational Evaluation of a Service for Prevention of Mother-to-Child Transmission of HIV in Rural Uganda. Tropical Medicine \& International Health, 15, 1163-1171. https://doi.org/10.1111/j.1365-3156.2010.02609.x

[17] Mandelbrot, L. (2011) Pregnancy and HIV Infection. HIV Edition, Paris, 587-614.

[18] Muchedzi, A., Chandisarewa, W., Keatinge, J., Chibanda, L.S., Woelk, G., Mbizvo, E. and Shetty, A.K. (2010) Factors Associated with Access to HIV Care and Treatment in a Prevention of Mother to Child Transmission Programme in Urban Zimbabwe. Journal of the International Aids Society, 13, 38.

https://doi.org/10.1186/1758-2652-13-38 